\title{
Direct-to-Consumer Prescription Drug Advertising and Patient-Provider Interactions
}

\author{
Helen W. Sullivan, PhD, MPH, Kathryn J. Aikin, PhD, Jennifer Berktold, PhD, \\ Karen L. Stein, PhD, and Victoria J. Hoverman, PhD
}

Background: Direct-to-consumer prescription drug advertising is prevalent and affects patient care. Previous research that examined its effect on the patient-provider relationship predates many changes in the advertising and medical landscape that have occurred in the last decade, such as the rise in online promotion and the push for value-based medicine.

Methods: We conducted a nationally representative mail-push-to-web survey of 1744 US adults in 2017 to explore how patients view the effects of direct-to-consumer prescription drug advertising on patient-provider interactions.

Results: Most respondents (76\%) said they were likely to ask a health care provider about advertised drugs; $26 \%$ said they had already done so. Among the $26 \%$ of respondents who talked to a health care provider about a specific prescription drug they saw advertised, $16 \%$ said they received a prescription for the advertised drug. Few respondents (5\%) reported that advertising had caused conflict with a health care provider, $16 \%$ said it had caused them to question their provider's advice, and $23 \%$ said they were likely to look for a different provider if their provider refused to prescribe a requested brand name drug.

Discussion: These results suggest that direct-to-consumer advertising is driving some patients to discuss specific products with their health care providers but that most patients do not believe advertising has a negative influence on the patient-provider interaction itself. (J Am Board Fam Med 2020;33:279-283.)

Keywords: Direct-to-Consumer Advertising, Health Personnel, Patient Care, Prescription Drugs, Surveys and Questionnaires

Direct-to-consumer advertising of prescription drugs (DTCA) is prevalent in the United States, with the amount spent on this advertising rising into the billions of dollars per year. ${ }^{1}$ This advertising is known to affect patient care. ${ }^{2}$ For instance, recent studies have found that DTCA increased the use of antidepressants, ${ }^{3}$ testosterone testing and use, ${ }^{4}$ high-cholesterol diagnosis and statin use in low-risk patients, ${ }^{5}$ prescribing of a smoking cessation product before safety issues were identified, ${ }^{6}$ and asthma medication prescription sales and asthma-related emergency

This article was externally peer reviewed.

Submitted 7 August 2019; revised 10 December 2019; accepted 15 December 2019.

From the US Food and Drug Administration, Silver Spring, MD (HWS, KJA); Westat, Rockville, MD (JB, KLS, VJH).

Funding: Funding was provided by the Office of Prescription Drug Promotion, US Food and Drug Administration.

Conflict of interest: The authors have no conflicts of interest to report.

Corresponding author: Helen W. Sullivan, $\mathrm{PhD}, \mathrm{MPH}$, US Food and Drug Administration, 10903 New Hampshire Ave., Silver Spring, MD 20993 (E-mail: Helen.sullivan@fda.hhs.gov). room visits. ${ }^{7}$ A recent systematic review of the literature on the effects of DTCA on patient-provider interactions ${ }^{8}$ identified both potential benefits, such as patients feeling more confident in their discussions with providers, ${ }^{9}$ and potential harms, such as patients reporting that DTCA led them to request prescription drugs. ${ }^{10}$ A limitation of this review is that most of the included studies were more than a decade old. As an example, the US Food and Drug Administration, which oversees DTCA to ensure it is truthful, balanced, and accurately communicated, ${ }^{11}$ last surveyed patients about the influence of DTCA on their interactions with health care providers (HCPs) in 2002. ${ }^{12}$ Declines in print readership, the rise in online promotion, and Pharmaceutical Research and Manufacturers of America guidelines have greatly altered DTCA in the last decade. Given the continued debate over DTCA, ${ }^{13}$ we examined how it currently affects patient-provider interactions from a patient perspective. 
Figure 1. National Survey of Health Information and Communication, 2017, data collection flow.

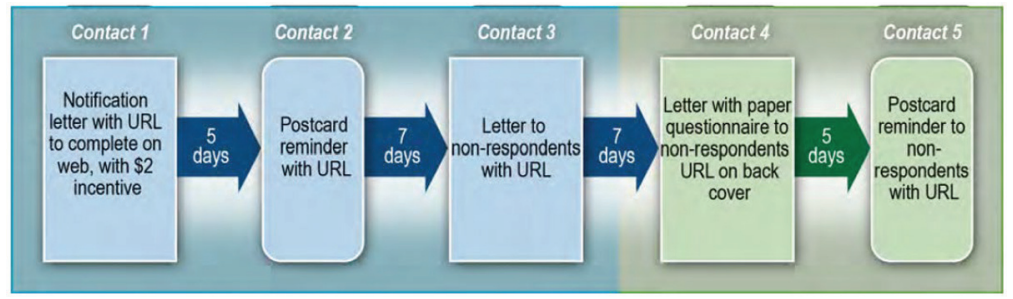

\section{Methods}

We conducted the National Survey of Health Information and Communication from October 10, 2017 to December 27, 2017. An address-based sample was drawn from the United States Postal Service Computerized Delivery Sequence File, which is comprehensive with good geographic detail, containing close to $100 \%$ of United States households. This allowed us to draw a probabilitybased, nationally representative sample of US households. We used a mail-push-to-web approach, initially inviting participants to complete the survey online, with a paper survey follow-up for nonresponders ${ }^{14}$ (see Figure 1). We used the HagenCollier within-household sampling scheme to identify a random adult (18 years of age or older) to complete the survey. ${ }^{15}$ The web portion of the survey was programmed in Verint and hosted by Westat. The mailed materials invited Spanish-language speakers to call a toll-free number to complete the survey in Spanish on the telephone. Respondents were provided a \$2 cash incentive in the first mailing that invited them to complete the survey.

A total of 7232 addresses were sampled and released for data collection. Of those addresses, a total of 1744 adults completed the survey, 435 were postal nondeliverables, 5023 did not respond, 28 refused, and 2 were ineligible. The response rate was $28 \%$. Table 1 shows the demographics of the sample, although note that the results are based on the weighted, nationally representative responses.

The survey asked respondents about their experiences with and attitudes toward DTCA. The initial pool of items included many items from previous surveys. Items were refined or deleted to create the final survey instrument based on a rigorous multistage design and development process, including an expert review panel, cognitive interviews, and a pretest with participants drawn by address-based sampling $(n=23)$.
Here, we report weighted frequencies. Weighting compensates for differential probabilities of selection, reduces biases due to differential nonresponse, and makes the estimates consistent with external population totals that are known from other sources. We used a classical design-based approach for weighting,

Table 1. Unweighted Demographic Characteristics of Respondents to the National Survey of Health Information and Communication, $2017(\mathrm{~N}=1,744)$

\begin{tabular}{lcc}
\hline Demographic & $\begin{array}{c}\text { No. of } \\
\text { Respondents }\end{array}$ & $\begin{array}{c}\text { \% of } \\
\text { Respondents }\end{array}$ \\
\hline Total & 1,744 & 100.0 \\
Age & & \\
18 to 34 & 262 & 15.3 \\
35 to 54 & 462 & 27.0 \\
55 to 64 & 419 & 24.5 \\
65 or older & 570 & 33.3 \\
Sex & & \\
Male & 691 & 40.4 \\
Female & 1,018 & 59.6 \\
Race/Ethnicity & & \\
White, non-Hispanic & 1,253 & 71.8 \\
Black, non-Hispanic & 99 & 5.7 \\
Hispanic & 101 & 5.8 \\
Other & 183 & 10.5 \\
Refused & 108 & 6.2 \\
Education & & \\
Less than high school & & \\
High school diploma or the & 280 & 17.0 \\
equivalent & & \\
Some college but not degree & 354 & 21.5 \\
Associate degree in college & 183 & 11.1 \\
Bachelor's degree & 456 & 27.7 \\
Advanced or postgraduate & 327 & 19.9 \\
degree & & \\
Have prescription drug coverage & & \\
with health insurance & & \\
Yes & & \\
No & & \\
No health insurance & & \\
\hline & & \\
\hline
\end{tabular}


Table 2. Questions about Patient-Provider Interactions from the National Survey of Health Information and Communication, 2017 ( $\mathrm{N}=1,744)$

\begin{tabular}{|c|c|c|c|c|c|}
\hline \multirow[b]{2}{*}{ Question or Statement } & \multicolumn{5}{|c|}{ Weighted Percentage of Answer } \\
\hline & Very Unlikely & Somewhat Unlikely & $\begin{array}{c}\text { Neither Likely Nor } \\
\text { Unlikely }\end{array}$ & $\begin{array}{l}\text { Somewhat } \\
\text { Likely }\end{array}$ & Very Likely \\
\hline $\begin{array}{l}\text { If you saw or heard an ad for a } \\
\text { drug that treats a medical } \\
\text { condition that was bothering } \\
\text { you, how likely would you be } \\
\text { to talk to your health care } \\
\text { provider about the drug? }\end{array}$ & 8.2 & 5.6 & 9.7 & 36.2 & 40.3 \\
\hline \multirow{2}{*}{$\begin{array}{l}\text { If a health care provider refused } \\
\text { to prescribe a brand name } \\
\text { drug you asked for, how likely } \\
\text { would you be to look for a } \\
\text { different health care provider? }\end{array}$} & 33.4 & 15.4 & 27.9 & 18.0 & 5.3 \\
\hline & Disagree strongly & Disagree somewhat & $\begin{array}{l}\text { Neither agree nor } \\
\text { disagree }\end{array}$ & Agree somewhat & Agree strongly \\
\hline $\begin{array}{l}\text { Ads for prescription drugs help } \\
\text { me have better discussions } \\
\text { with my health care provider } \\
\text { about my health. }\end{array}$ & 15.5 & 12.2 & 38.0 & 25.9 & 8.4 \\
\hline $\begin{array}{l}\text { Ads for prescription drugs make } \\
\text { it seem like a doctor is not } \\
\text { needed to decide whether a } \\
\text { drug is right for me. }\end{array}$ & 22.2 & 18.0 & 25.0 & 22.4 & 12.4 \\
\hline
\end{tabular}

beginning with base weights that are the inverse of the probability of selection, and including nonresponse and demographic weights. The demographic control totals used in the raking used American Community Survey data as the benchmark.

\section{Results}

See Tables 2 and 3 for all results.

\section{Patient Requests and Patient-Reported Prescribing for Prescription Drugs}

Most respondents (76\%) reported that they were likely to talk to their HCP about a prescription drug based on advertising. Approximately one-quarter of respondents (26\%) reported that they had already done so. Of those, one-third (33\%) asked their HCP to prescribe the advertised drug. Among the $26 \%$ of respondents who talked about a specific prescription drug they saw advertised, $16 \%$ said they received a prescription for the advertised drug. This means that approximately $4 \%$ of all respondents received a specific prescription drug they discussed with their HCP because they saw it advertised.

\section{Positive Effects of DTCA}

Approximately one-third of respondents (34\%) agreed prescription drug ads helped them have better discussions with their HCP. Some respondents reported prescription drug advertising led them to talk with an HCP about a new medical condition (20\%), their symptoms (35\%), and drug side effects they experienced (27\%).

\section{Negative Effects of DTCA}

Although few respondents reported that advertising had caused conflict with an HCP (5\%), 16\% said it had caused them to question their HCP's advice, and $23 \%$ said they were likely to look for a different HCP if their HCP refused to prescribe a requested brand name drug. Approximately one-third of participants (35\%) agreed that prescription drug ads make it seem like a doctor is not needed when deciding if a prescription drug is right for them to take.

\section{Discussion}

As DTCA promotion has grown over the past few decades, its positive and negative influences on health care have been debated. ${ }^{16}$ This nationally representative survey updates the literature by providing insight into how patients currently view the effects of this advertising on prescribing and their interactions with HCPs. 


\begin{tabular}{|c|c|c|c|}
\hline \multirow[b]{2}{*}{ Question or Statement } & \multicolumn{3}{|c|}{ Weighted Percentage of Answer } \\
\hline & Yes & No & Do Not Know \\
\hline $\begin{array}{l}\text { As a result of seeing or hearing an ad for a prescription drug, have you ever talked } \\
\text { with a health care provider about a medical condition or illness that you had not } \\
\text { talked to a health care provider about before? }\end{array}$ & 20.1 & 71.1 & 8.8 \\
\hline $\begin{array}{l}\text { As a result of seeing or hearing an ad for a prescription drug, have you ever talked } \\
\text { with a health care provider about a specific prescription drug you saw or heard } \\
\text { advertised? }\end{array}$ & 26.1 & 70.0 & 3.9 \\
\hline $\begin{array}{l}\text { If yes*: Did you specifically ask a health care provider to prescribe the drug you saw } \\
\text { or heard advertised? }\end{array}$ & 32.5 & 63.5 & 4.0 \\
\hline \multicolumn{4}{|l|}{ If yes*: Did the health care provider... } \\
\hline Recommend lifestyle changes, such as getting more exercise or changes in diet. & 60.0 & N/A & N/A \\
\hline Give you a prescription for the drug you saw or heard advertised. & 16.1 & N/A & N/A \\
\hline Give you a prescription for a different drug. & 21.9 & N/A & N/A \\
\hline Not give you any prescription at all. & 42.6 & N/A & N/A \\
\hline \multicolumn{4}{|l|}{ Prescription drug advertising has caused me to: } \\
\hline Talk with my health care provider about symptoms I've experienced. & 34.6 & 65.4 & N/A \\
\hline Talk with my health care provider about drug side effects I've experienced. & 27.4 & 72.6 & N/A \\
\hline Question the advice of my health care provider. & 16.0 & 84.0 & N/A \\
\hline Experience conflict with a health care provider. & 4.8 & 95.2 & N/A \\
\hline
\end{tabular}

*These questions were asked of the subset of respondents who answered "yes" to the question "As a result of seeing or hearing an ad for a prescription drug, have you ever talked with a health care provider about a specific prescription drug you saw or heard advertised?" Percentages reflect the weighted proportion of the subset who gave each response.

Consistent with previous surveys, this survey found that DTCA prompts some patients to discuss medical conditions and request advertised drugs. ${ }^{8}$ However, a providers' willingness to prescribe patient-requested drugs may have decreased over time. In 2002, $23 \%$ of respondents who saw a provider in the last 3 months asked whether there was a prescription drug to treat them, and $49 \%$ of them were given the prescription drug they asked about. ${ }^{12}$ In 2017, the majority of respondents (60\%) who asked their HCP about an advertised drug reported that their HCP recommended lifestyle changes such as diet and exercise to them, whereas only $16 \%$ of respondents reported that their HCP prescribed the advertised prescription drug. Although the two surveys are not directly comparable, this suggests a decrease in the number of patients receiving requested drugs. Moreover, a refusal to prescribe an advertised prescription drug did not seem to have overtly adverse effects on the patient-provider relationship, such as motivating respondents to look for a different health care provider. These findings may reflect a shift in the larger health care paradigm toward formularies and value-based medicine, in which HCPs are focused on improving patients' health by providing cost-effective, quality care, while balancing patient satisfaction. ${ }^{17}$

Some respondents reported that DTCA improved discussions and prompted conversations about symptoms and drug side effects. Others reported negative effects on the patient-provider interaction, like questioning advice. These findings demonstrate that, despite changes to the DTCA landscape, patients are still experiencing the positive and negative effects of DTCA that have been debated for decades. ${ }^{13}$

A few limitations should be noted. First, in keeping with the decline in survey response rates, ${ }^{18}$ this survey had a low response rate. This survey used weighting to address the potential for nonresponse bias. Second, the survey reflects only one side of the patient-provider interaction: the patient's. The survey does not explain the reasoning behind the HCPs' prescribing decisions. ${ }^{19,20}$ These data should be considered along with HCP surveys and studies that link patient requests to prescribing rates. ${ }^{21}$ Finally, like other surveys of this topic, this survey collected retrospective accounts of patientprovider interactions; respondents may have misremembered the impact DTCA had on their discussions with their HCPs. Research that examines the 
patient-provider interaction itself, by recording real-life interactions, for example, would provide a more accurate and thorough understanding of the effects of DTCA. ${ }^{22}$

DTCA is atypical compared to other types of advertising because HCPs are a required intermediary for patients to gain access to the product. This unique circumstance provides opportunities and challenges for HCPs seeking to provide optimal care to their patients. ${ }^{23}$ Consideration of patient attitudes toward DTCA and its potential impact on the patient-provider relationship could help HCPs, pharmaceutical companies, patients, and other stakeholders to foster good health outcomes.

To see this article online, please go to: http://jabfm.org/content/ 33/2/279.full.

\section{References}

1. Schwartz LM, Woloshin S. Medical marketing in the United States, 1997-2016. JAMA. 2019;321:8096.

2. Mintzes B. Advertising of prescription-only medicines to the public: does evidence of benefit counterbalance harm? Annu Rev Public Health. 2012;33:259-277.

3. Avery RJ, Eisenberg MD, Simon KI. The impact of direct-to-consumer television and magazine advertising on antidepressant use. J Health Econ. 2012;31:705-718.

4. Layton JB, Kim Y, Alexander GC, Emery SL. Association between direct-to-consumer advertising and testosterone testing and initiation in the United States, 2009-2013. JAMA. 2017;317:1159-1166.

5. Niederdeppe J, Byrne S, Avery RJ, Cantor J. Direct-to-consumer television advertising exposure, diagnosis with high cholesterol, and statin use. J Gen Intern Med. 2013;28:886-893.

6. Kim Y, Kornfield R, Shi Y, et al. Effects of televised direct-to-consumer advertising for varenicline on prescription dispensing in the United States, 20062009. Nicotine Tob Res. 2016;18:1180-1187.

7. Daubresse M, Hutfless S, Kim Y, et al. Effect of direct-to-consumer advertising on asthma medication sales and healthcare use. Am J Respir Crit Care Med. 2015;192:40-46.

8. DeFrank JT, Berkman ND, Kahwati L, Cullen K, Aikin KJ, Sullivan HW. Direct-to-consumer advertising of prescription drugs and the patient-prescriber encounter: a systematic review. Health Commun. 2019;1-8.

9. Murray E, Lo B, Pollack L, Donelan K, Lee K. Direct-to-consumer advertising: public perceptions of its effects on health behaviors, health care, and the doctor-patient relationship. J Am Board Fam Pract. 2004;17:6-18.

10. Lee D, Begley CE. Racial and ethnic disparities in response to direct-to-consumer advertising. Am J Health-Syst Pharm. 2010;67:1185-1190.

11. US Food and Drug Administration. The Office of Prescription Drug Promotion (OPDP). https:// www.fda.gov/about-fda/center-drug-evaluation-andresearch-cder/office-prescription-drug-promotionopdp. Updated November 4, 2019. Accessed November 21, 2019.

12. Aikin KJ, Swasy JL, Braman AC. Patient and physician attitudes and behaviors associated with DTC promotion of prescription drugs-summary of FDA survey research results. Washington, DC: Food and Drug Administration; 2004.

13. Parekh N, Shrank WH. Dangers and opportunities of direct-to-consumer advertising. J Gen Intern Med. 2018;33:586-587.

14. Dillman DA, Smyth JD, Christian LM. Internet, phone, mail, and mixed-mode surveys: the tailored design method. 4th ed. Hoboken, NJ: John Wiley \& Sons; 2014.

15. Gaziano C. Comparative analysis of within-household respondent selection techniques. Public Opin Q. 2005;69:124-157.

16. Ventola CL. Direct-to-consumer pharmaceutical advertising: therapeutic or toxic? Pharm Ther. 2011;36:669-674, 681-684.

17. Bae J. Value-based medicine: concepts and application. Epidemiol Health. 2015;37: e2015014.

18. National Research Council. Tourangeau R, Plewes TJ, editors. Nonresponse in social science surveys: a research agenda. Washington, DC: The National Academies Press; 2013.

19. Campbell EG, Pham-Kanter G, Vogeli C, Iezzoni LI. Physician acquiescence to patient demands for brand-name drugs: results of a national survey of physicians. JAMA Intern Med. 2013;173:237-239.

20. Menchik DA, Jin L. When do doctors follow patients' orders? Organizational mechanisms of physician influence. Soc Sci Res. 2014;48:171-184.

21. Murshid MA, Mohaidin Z, Yen Nee G. The influence patient's characteristics "requests and expectations" on physician prescribing behavior: a review. Int J Pharm Health Mark. 2016;10:390-411.

22. McKinlay JB, Trachtenberg F, Marceau LD, Katz JN, Fischer MA. Effects of patient medication requests on physician prescribing behavior: results of a factorial experiment. Med Care. 2014;52:294299.

23. Ortiz SE, Rosenthal MB. Medical marketing, trust, and the patient-physician relationship. JAMA. 2019;321:40-41. 